Article

\title{
Vocabulary Research in the Modern Language Journal: A Bibliometric Analysis
}

\author{
Paul M. Meara \\ Swansea University and Cardiff University \\ doi: http://dx.doi.org/10.7820/vli.v03.1.meara
}

\begin{abstract}
This paper reports a bibliometric analysis of a set of 201 articles which was published in The Modern Language Journal (MLJ) between 1916 and 2010. All these articles deal with vocabulary acquisition. The paper reports an all-inclusive author co-citation analysis of this data, in an attempt to sketch out the historical development of vocabulary acquisition research. The paper presents a set of maps which shows whose work is being cited in the Journal. Co-citation links between cited sources allow us to identify research clusters which are characterised by patterns of citations. This paper uses these maps to show how the predominant research focus has changed significantly over the period studied. Much of the earlier work published in MLJ no longer figures in more recent research. The more recent research appears to be much more inward-looking and self-referential than is the case for the earlier research. This paper suggests that a co-citation analysis of research in a single journal does not capture the full richness of vocabulary research, which in turn raises some interesting questions about the selectivity of journals and their research biases.
\end{abstract}

\section{Introduction}

The massive increase in research outputs in the last 20 or 30 years has given rise to a growing interest in bibliometric techniques that can provide coherent accounts of the main trends in a large body of work that might otherwise be intractable. One of the best established methods of doing this appears to be the cocitation model developed by Small (1973) in a number of papers published in the 1970s. This work, which was actually built on earlier bibliometric work by Price (1965), has been extensively used to analyse research in the natural sciences (e.g., White \& Griffith, 1981) but does not seem to have been adopted as a standard tool by researchers in the Humanities (Hellqvist, 2010). My own interest lies in the area of vocabulary acquisition by second-language learners, and I have used the cocitation method to successfully generate analyses of small parts of the research literature in this area. Specifically, I have analysed the entire research output for 1982 and 2006. This work, reported in Meara (2012, forthcoming), is interesting in that it provides snapshots of the research that was taking place in these years, and allows us to identify research foci within the wider research community (Price, 1986; Zuccala, 2006). These foci are clusters of researchers - people who tend to be cited together in the same papers and represent a thematic feature within a research landscape. 
Doing an exhaustive analysis of this sort is not as simple as it sounds. The main problem is that we can never be sure that we have in fact identified all the relevant research published in a single year. For L2 vocabulary research, the best source is the Vocabulary Acquisition Research Group Archive (VARGA) database (Meara, n.d.). This database is a very large bibliographic source that contains some 5000 papers dealing with L2 vocabulary acquisition, and is probably the closest thing we have to a comprehensive listing. ${ }^{1}$ However, even a well-maintained resource of this sort is, in the last analysis, only a personal bibliography, and we cannot be sure that it has recorded every piece of research that is to be had. VARGA is good on English-language research, Dutch-language research and Spanish-language research, but its coverage of research in other languages, particularly German and Chinese sources, is less reliable. Furthermore, VARGA's attempts to provide comprehensive coverage means that it contains a lot of derivative literature which many researchers would not consider to be cutting-edge work. This introduces some interesting biases into the citation patterns: for example, it tends to give more prominence to secondary sources, and downplays the importance of seminal work that is well known to only a few key researchers, but not widely known to people working on more routine research topics. More importantly, when we analyse the work published in a single year, the resulting snapshots fail to capture the dynamics of the research activity - how research in vocabulary acquisition changes its focus over time, how some authors make longterm contributions to the field, how other authors flourish only briefly before their influence fades away, how the field persistently fails to follow up important ideas and so on. In order to investigate these ideas, we need to make a longitudinal study of vocabulary research rather than a cross-sectional one.

Doing a complete longitudinal analysis of all the work included in a database like VARGA would be a massive undertaking, but we can make a first stab at a historical account of L2 vocabulary research by looking at all the relevant research published in a single long-running journal. Using as source material papers published in a single journal provides us with a tractable set of data which is comprehensive in a limited kind of way. It also solves the problem of quality, in that articles which appear in a high quality scholarly journal come with some sort of guarantee that the editors, at least, think these papers deal with important topics that are relevant to their readers' interests. Hopefully, a complete analysis of this sort might serve as a framework on which other, more specific analyses can be positioned.

This paper, then, presents a bibliometric analysis of the vocabulary research published in a single journal, and the question we are asking is whether data of this sort can provide a basic historical framework that can be used as scaffolding for further studies on how researchers have approached L2 vocabulary acquisition over an extended period. The journal selected for analysis is The Modern Language Journal (MLJ). MLJ is a good candidate for a study of this sort. It first appeared in 1916 and has an unbroken history of publication since that date. MLJ rapidly established itself as the flagship journal of the Modern Language Association (MLA) and it attracted submissions from people who in their day would have been considered major figures in the field. It is currently rated as 16 out of 121 Linguistics Journals according to the ISI Journal Citation Reports - a very significant achievement when we consider that the Linguistics list includes a 
number of very heavyweight publications. MLJ is not particularly partisan from a theoretical point of view, but it does seem to be closely in touch with contemporary developments in research and responds quickly to new developments, such as the growth of Computer Assisted Language Learning (CALL), or the emergence of a new geopolitically significant language. More importantly, from our point of view, is that the journal has consistently shown an interest in vocabulary research over its long history. In recent years, it has published a number of papers which have gone on to become very influential in vocabulary research, and a surprisingly large number of the Significant Influences in vocabulary research that were identified in my 2012 paper have appeared as authors in its pages.

\section{Methodology}

Although it seems a straightforward matter to identify vocabulary-related research in a single journal, in practice this process is more subjective than it appears. Research practice between 1916 and 2010 is far from consistent. Few of the early papers contain any empirical data, for example, and many of these studies are little more than short opinion pieces, critical of other scholars' work, but not always providing good evidence for their authors' views. There are also a few pieces which deal with vocabulary acquisition alongside other questions - reading, vocabulary and grammar, for instance - and with these papers it was necessary to make a judgement call as to whether their vocabulary content was sufficient for them to be included or not. I eventually identified a total of 201 papers whose main focus appeared to be vocabulary, published in MLJ between 1916 and 2010. This works out to two or three papers per year - though it is worth noting that the distribution of papers is far from uniform, and there is a particularly striking falloff in vocabulary research between 1940 and 1980 (see Figure 1). For reasons which

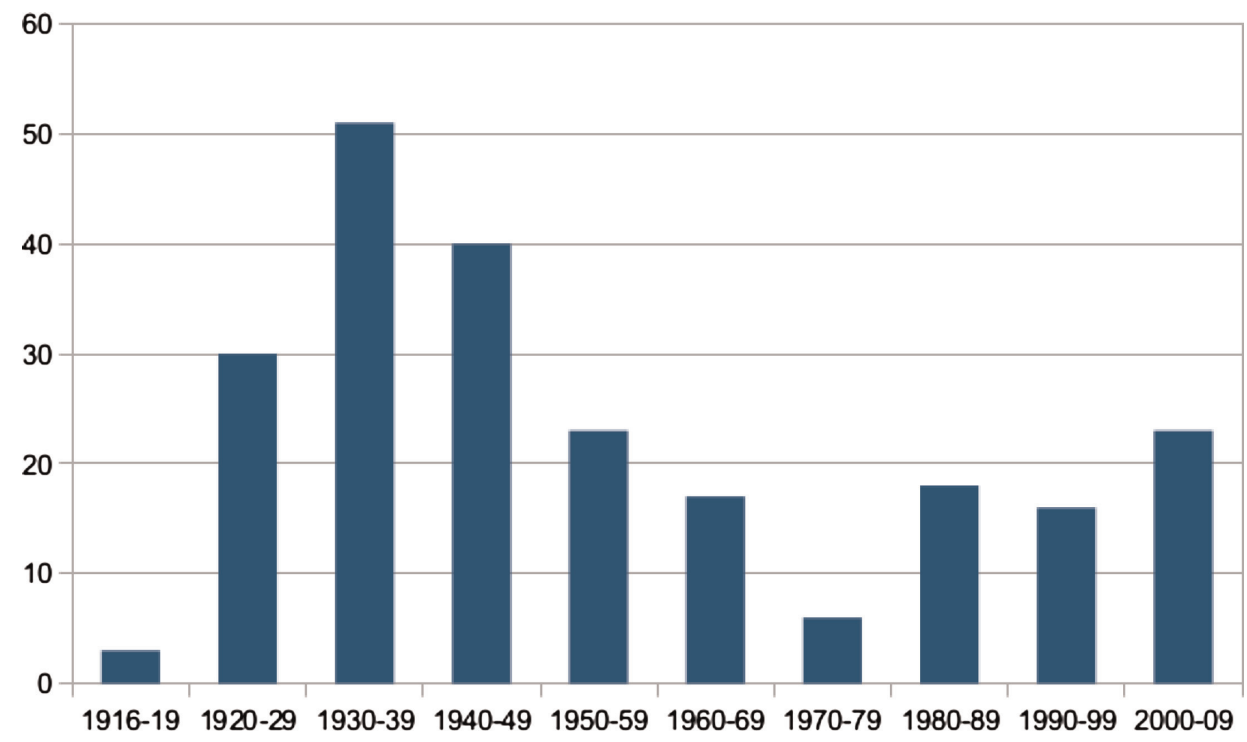

Figure 1. Papers whose main focus is vocabulary: The Modern Language Journal 1916-2010. 
will become obvious as this paper progresses, the entire list of 201 sources is not included in the bibliography at the end of this paper but a complete listing is included as an Appendix to this paper.

The raw data for a co-citation analysis consists of a list of all the authors cited in the set of papers to be analysed. For each paper in the data set, we make a list of every author that the paper cites; for each paper, each cited author counts only once, regardless of how many times they are cited in the paper; and for a cited paper with multiple authors, each of the contributors is added to the author list. Normally, this process is a purely mechanical one, which consists of extracting a machine-readable author list from a set of references at the end of the article. In the case of MLJ, this straightforward data collection turned out to be surprisingly difficult. Modern citation practices were not adopted by the journal until the 1970s, and earlier volumes often do not have proper bibliographies. A surprising number of early papers have no references at all, and where they do the references are sometimes cursory and incomplete. For instance, the text may refer to "a recent comment by a well-known Professor", without giving any bibliographical details. This meant that the only way to construct the complete author list was to read the papers and extract the data manually.

Once this work was complete, I developed a computer programme to generate the necessary co-citation lists. Numerate readers will realise that the amount of data generated in this way is very large, as the number of co-citations is an exponential function of the number of authors cited in a paper. An author list of only five people generates a set of 10 co-cited pairs $(5 * 4 / 2=10)$, a list of 20 authors generates $20 * 19 / 2=190$ co-cited pairs, while a list of 100 authors generates $100 * 99$ / $2=4950$ co-citations. Generally speaking, the early papers in MLJ cite only a few references, but the more recent articles have very extensive reference sets. The average number of citations over the entire set of 201 papers is 19 , generating a set of 113,071 co-citations. Fortunately, there are available a number of network mapping programmes which allow data sets of this size to be processed relatively easily. In this paper, I have used a programme called Gephi (Bastian, Heymann, \& Jacomy, 2009). Gephi performs a cluster analysis on the data and groups together authors who tend to be cited alongside each other in a number of papers. The clusters are taken to represent groups of researchers who share similar concerns.

\section{Results}

Gephi's output for the entire data set is shown in Figure 2. ${ }^{2}$

In this figure, the nodes represent individual authors, and the lines linking the nodes show the co-citations. The size of the nodes reflects the number of other sources each author is associated with, and the width of the links shows the frequency of the co-citations. The colour of the nodes indicates the clusters identified by Gephi. The raw data have been greatly simplified by the exclusion of authors who are cited in fewer than three texts or appear in fewer than three cocitations. However, even this simplified data is extremely complex: the graph contains 4833 co-citations linking 296 authors. It is immediately obvious that some of the authors cluster together into large clumps, while others are more peripheral or belong to detached clusters. In fact, Gephi has identified a total of six distinct 


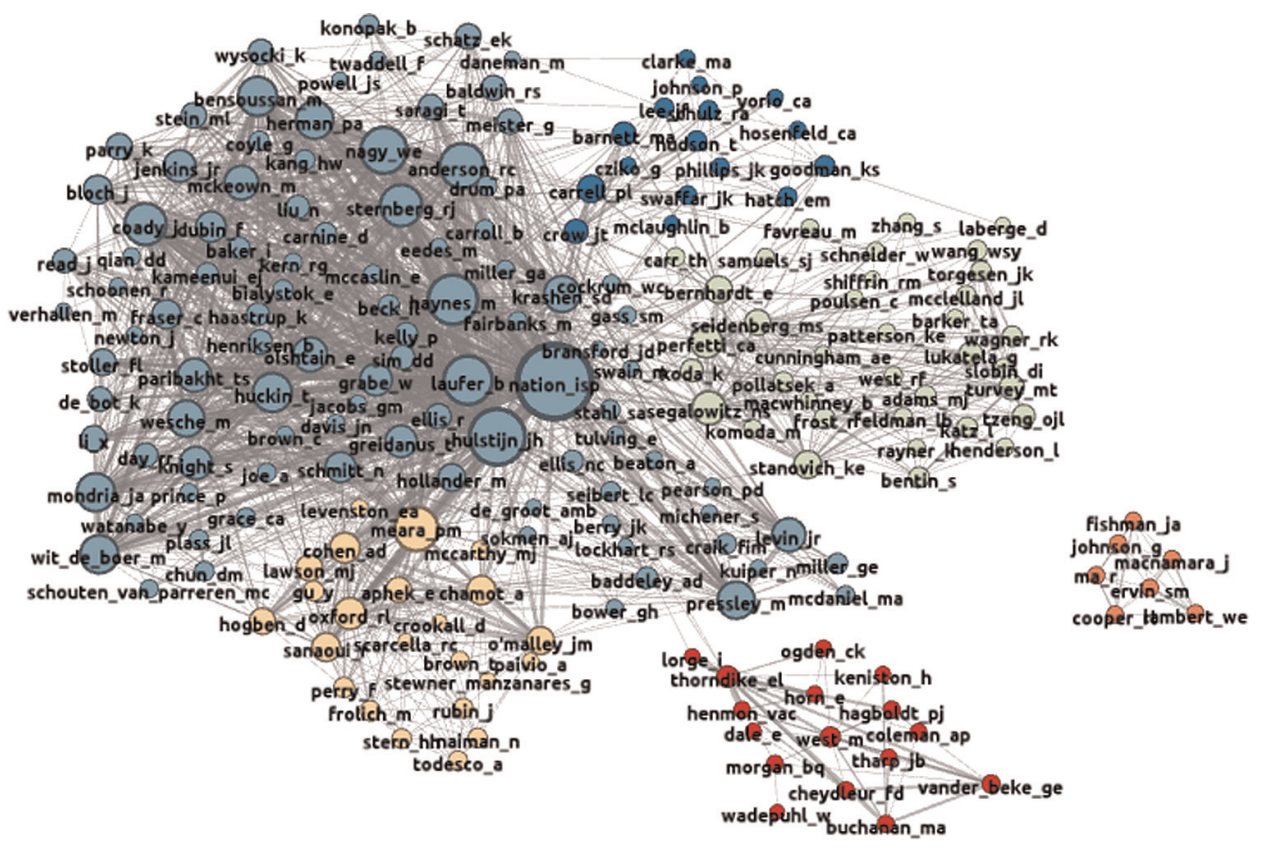

Figure 2. Co-citation analysis of vocabulary-related articles 1916-2010. Threshold for inclusion: three co-citations.

research clusters in this data. The complex nature of the data presented in Figure 2 makes it difficult to interpret these clusters, but we can simplify the task by extracting the data from a number of thin time-slices, before returning to the full picture at a later point. This is done in the following sections.

\subsection{6-1950}

My original intention was to analyse the MLJ data in a set of 10-year windows, but this strategy was foiled by the very low level of citations in the early papers. In fact, the best we can do with the early papers is to group together all the work published between 1916 and 1950. This gives us a set of 102 papers - just over half of the data set. However, 25 of these papers contain no citations, and the average number of citations for the remaining 77 papers is a mere 5.8. Figure 3 shows Gephi's analysis of this data.

This map is made up of 134 co-citation links identifying 41 sources in three clusters. The clusters in Figure 3 can be easily described.

Cluster I, the central cluster focussed on West and Thorndike, is made up of 34 sources that have an interest in the development of word frequency counts for L2 learners. West is a very significant figure in English-language teaching and responsible for the influential General Service List of English Words published in 1953. Thorndike will be familiar to most readers for his work on the Thorndike and Lorge frequency count published in 1944, a text which was a standard reference tool in psycholinguistics well into the 1970s. However, Thorndike was not 


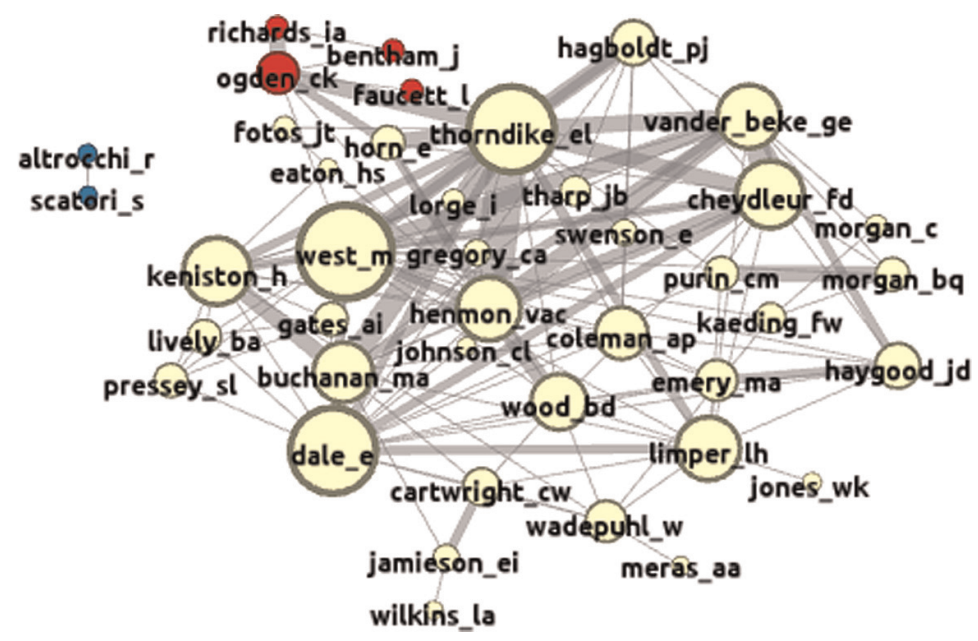

Figure 3. Co-citation analysis of vocabulary focussed articles 1916-1950. Threshold for inclusion: two co-citations. The Significant Influences 1916-1950: West, Thorndike, Dale, Keniston, Cheydleur, Henmon, Limper, Vander Beke, Buchanan, Wood, Coleman, Haygood, Hagboldt, Emery and Ogden.

principally a linguist: his main contribution to research at this time was in the psychology of learning and the measurement of cognitive skills, and a number of other sources cluster with Thorndike because of their work as educational psychologists interested in assessing vocabulary knowledge. Henmon published a frequency count for French, but like Thorndike he was basically a psychologist - he had worked with James McKean Cattell, one of the pioneers of psycholinguistic research. Horn was also an educational psychologist, particularly interested in children's vocabulary. He published a number of early word counts in the 1920s. Dale is mainly concerned with evaluating the difficulty of reading texts, and he worked with Irvin Lorge on a readability index for English. Dale's work on English is often cited in the context of L2 vocabulary acquisition because he is mainly interested in the implications of frequency-based word lists for teaching high-level reading courses, and this has some obvious implications for advanced L2 speakers. The other people in this cluster will probably be less familiar to readers. Keniston and Buchanan developed early word counts for Spanish, Vander Beke and Hagboldt worked on German, Cheydleur worked on French and was also influential in the development of language testing. The striking feature of this cluster is how closely the sources are interconnected. The cluster is basically a "theoretical core" of people working on the principles of word counts, and an extended periphery which tries to implement these principles in word counts for specific languages.

Cluster II, with four sources, is focussed on Ogden and Richards, the originators of BASIC English. BASIC addresses the same problems that form the focus of Cluster I, but solves these problems by developing a very small core vocabulary for English, which is largely independent of the available frequency counts.

Cluster III is a small detached cluster which comprises people who are interested in cognates and the role they might play in vocabulary learning. 
A number of features are worth pointing out in these data. The first notable feature of this map is that almost all the work produced during this very long period falls into a single cluster that is predominantly concerned with word counts and their applications. This cluster consists of a densely connected core and a periphery of people who are less densely connected to this core or with each other. The periphery seems to consist of people who are actively involved in teaching languages, while the core of the cluster seems to consist of external reference points - people who work on vocabulary, but are not part of the ongoing debate about L2 vocabulary needs which characterises the periphery. However, the pattern of connections suggests that these external reference points are strongly linked to the rest of the cluster, and I interpret this to mean that the L2 researchers in Cluster I are very aware of work that is going on outside their own fields, and open to its influence. The second feature of this map is the way that the research on the main foreign languages - French, German, Spanish and to a lesser extent Italian - is not at all compartmentalised. People working on one language seem to be very much aware of developments in the other languages, and there is no evidence here of the split between Modern Languages and English Language Teaching (ELT) which is a common feature of more recent research. The third feature worth noting is the detached Cluster III. Given the importance of cognates for L2 learners, it is very surprising that Altrocchi and Scatori are not better connected to the main cluster. This separateness may be due to the fact that Altrocchi and Scatori are principally interested in Italian, a language which is not otherwise well represented in the main cluster.

The legend to Figure 3 lists 15 people who I have designated as "Significant Influences" in this period - the best connected nodes in the map. This list is surprising in a number of ways. The first surprising feature is that only a handful of these names will be familiar to modern readers: West, Thorndike and Ogden stand out in this respect. The other Significant Influences in this period are much less familiar - their work is rarely cited in modern research. This immediately raises the question of why this work has been forgotten. The second feature is the emergence of Michael West as the most Significant Influence during this period. West remains an important reference point for ELT researchers (Smith, 2003), but I suspect that his work might not be familiar to most teachers of modern languages. This raises some interesting questions about the relationship between ELT and modern language teaching during this early period, specifically why ELT and modern language teaching seem to have diverged in their approaches to vocabulary. The third surprising feature is the fact that two of the most Significant Influences for this period are primarily educational psychologists with only a tangential interest in L2 vocabulary, and that a number of other Significant Influences, notably Henmon and Limper, were also active researchers in this wider area. The implication of this is that vocabulary research during this period is not an inward-looking research activity. On the contrary, the field, small though it is, has strong connections to wider research interests.

\section{$3.2 \quad 1951-1980$}

Given this promising beginning, we might expect that vocabulary research after 1950 would have developed strongly, but, as we see in Figure 1, what we 
actually get is a period of steady decline. In fact, between 1951 and 1980, MLJ published only 42 papers dealing with vocabulary issues - only three papers every two years. It is not clear whether this represents a much wider, general shift away from vocabulary research, or one that is specific to MLJ. Only further analysis of other sources can answer this question. In the meanwhile, the MLJ data will be taken at face value, and a co-citation analysis of this data is shown in Figure 4. Given the small number of papers, and the low level of citations in these papers (the average number of citations is around 10, but only 16 papers reach double figures), this analysis needs to be treated with appropriate caution.

The analysis has identified six clusters for this period.

Cluster I, the small cluster in the north-west corner of the map, will be familiar from Figure 3. This cluster is the remains of the large cluster that dominated the research in the 1916-1950 period. Significantly, this work has now become detached from the main lines of research.

Clusters II and III, the two small clusters at the south-west of the map focussed on Carroll, also provide a link with the earlier work. Carroll is a new figure, but all the other members of these clusters - Hagboldt, Morgan, Thorndike, Lorge, Fries and Borroughs - appeared in the earlier map. Their influence is much diminished, however, and only Carroll's links with the main cluster prevents these clusters from joining Cluster I in the wilderness. The three remaining clusters are all composed of new names that did not appear in the earlier map.

Cluster IV, the smaller cluster on the western edge of the map, is a group of psychologists focussed around Jenkins. This group is predominantly interested in word associations in L1 speakers. They are not interested in L2 vocabulary, but

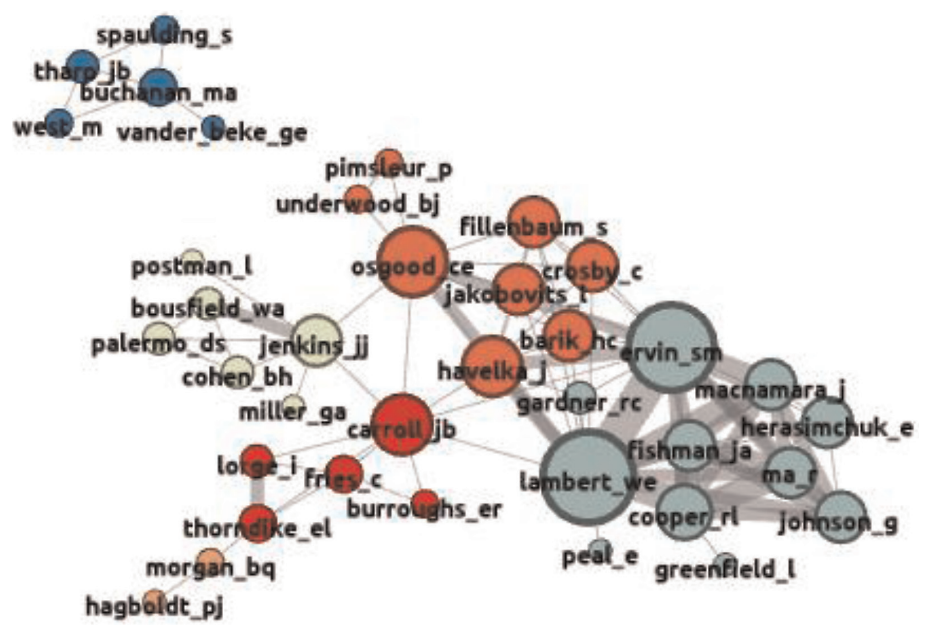

Figure 4. Co-citation analysis of vocabulary-focussed articles 1951-1980. Threshold for inclusion: two co-citations. The Significant Influences 1951-1980: Lambert, Ervin, Os-good, Havelka, Carroll, Cooper, Barik, Ma, Crosby, Johnson, Macnamara, Jenkins, Fishman, Herasimchuk, and Jakobovits. 
their methods are often used by other researchers who use the word association methodology with L2 speakers and bilinguals.

The two remaining clusters represent an approach to L2 vocabulary which is very different from anything we see in Figure 3.

Cluster V, focussed on Lambert and Ervin, is a social psychology cluster. Lambert and his colleagues in Montreal were particularly interested in developing measures of language dominance in English-French bilinguals, and many of the test types that they explored were basically measures of vocabulary skills in these languages. This cluster also contains a group of sociolinguists centred around Fishman, and based in New York. This group was particularly interested in Hispanic speakers and used vocabulary data as a way of evaluating the way their subjects used English and Spanish in their everyday lives. This cluster, then, is really concerned with bilinguals in two very specific sociolinguistic contexts.

The final cluster, Cluster VI, is more difficult to characterise. Like Cluster V, this cluster is composed of psychologists, but the focus of this group is on cognitive psychology rather than social psychology. A particular concern of this cluster is the psychology of meaning.

Figure 4 suggests that the research published in MLJ during this period has not developed in the way we might have expected. There has been a significant shift away from word lists and frequency counts and a marked rise in psychological research. However, most of this work is not concerned with vocabulary acquisition: in the main clusters, only Pimsleur (Cluster VI) has an interest in language teaching. The other researchers are focussed on the behaviour of bilinguals. This interpretation throws a very stark light on vocabulary research during this period. We have already seen in Figure 1 that MLJ published very little vocabulary research between 1951 and 1980, and if we discount the papers by Lambert and Cook which furnish most of the co-citations that identify Clusters IV, V and VI, then we are left with two very small disconnected research islands. This shift in focus is reflected in the list of Significant Influences for this period (see the legend to Figure 4). None of the Significant Influences from the 1916 to 1950 period continues to be influential in the 1951-1980 - even major figures like Thorndike and West drop out of the Significant Influence table. More important, perhaps, is the fact that few of the Significant Influences for 1951-1980 will be familiar to modern researchers, and this provides a hint that the psycholinguistic and sociolinguistic approaches that dominate the 1951-1980 period have not left a lasting impression on L2 vocabulary acquisition research.

\section{$3.3 \quad 1981-2000$}

This conclusion is broadly confirmed by Figure 5, which shows an analysis of the 35 relevant papers published in MLJ between 1981 and 2000. Citation rates during this period are considerably higher than in the earlier periods - the average number of cited authors in these papers is 43.4. Consequently, I have adjusted the threshold for inclusion to take account of this. The map is based on a set of 418 co-citations which appear at least three times in the data set. These co-citations 


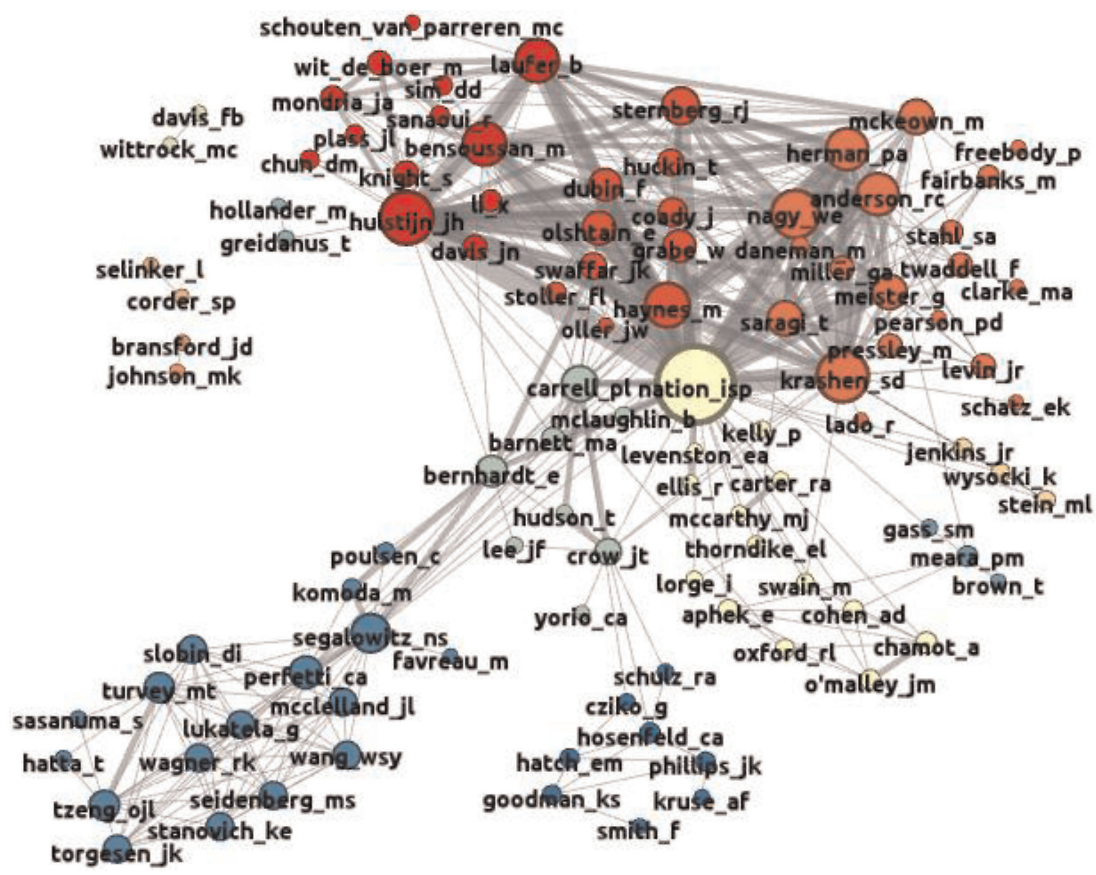

Figure 5. Co-citation analysis of vocabulary-focussed articles 1981-2000. Threshold for inclusion: three co-citations. The Significant Influences 1981-2000: Nation, Hulstijn, Krashen, Nagy, Haynes, Bensoussan, Laufer, Anderson, Herman, Segalowitz, Sternberg, Carrell, Meister, and McKeown.

identify 103 authors grouped into 13 clusters. Three of these clusters are detached from the main cluster grouping.

Again, the clusters are easily interpreted.

Cluster I, in the north-east corner of the map, is the largest cluster in this map. It contains six of the Significant Influences from this period (Anderson, Krashen, McKeown, Meister, Nagy and Herman). This cluster is mainly concerned with the differences between explicit vocabulary acquisition and incidental vocabulary acquisition from extended texts. Particularly striking is the large number of L1 reading researchers in this cluster. The cluster is very closely linked with Cluster IV.

Cluster II, the second largest cluster in the south-west corner of the map, is focussed on Segalowitz. This cluster is basically a group of psychologists with an interest in language processing. Most of these people do not work on L2 speakers, and the group as a whole is connected to the main clusters only through Segalowitz, Poulsen and Komoda's work on non-native speakers' performance.

Cluster III, the central cluster focussed on Nation, seems mainly to consist of people with an interest in Corpora and their implications for vocabulary acquisition, and a small group of people with an interest in vocabulary strategies. Nation's work on frequency counts explains his inclusion in this cluster. Nation is also massively cited alongside the members of Clusters I and IV, but the other members of this cluster have only weak links to other parts of the map. 
Cluster IV, at the top edge of the map, contains three of the Significant Influences of this period (Hulstijn, Laufer and Bensoussan). This group is broadly interested in the factors which facilitate or inhibit the acquisition of L2 vocabulary. Knight, Davis, Chun and Plass represent a subgroup of researchers who deal with glosses.

Cluster V, focussed on Haynes and Sternberg, seems to be mainly concerned with reading in an $\mathrm{L} 2$, but this cluster is very tightly bound to the two large clusters: I and IV.

Cluster VI, at the southern edge of the map, is another reading cluster mainly composed of $\mathrm{L} 1$ reading theorists. It is notable that this cluster does not seem to have any links with L1 reading theorists who appear in Cluster I.

Cluster VII, focussed on Carrell and Bernhardt, is another reading cluster. I think this cluster is distinguished from the earlier clusters by an interest in Graded Readers. This cluster plays an important role in providing the links which prevent this map from fragmenting into disconnected clusters. The co-citations linking Segalowitz and Bernhardt, Crow and the L1-reading theorists in Cluster VI and Carrell's links with the clusters at the top of the map are particularly important in this regard.

Cluster VIII, Stein, Wysocki and Jenkins, has links with Nation and Krashen but is otherwise detached from the main cluster. This group were the authors of a 1984 paper dealing with the acquisition of L1 vocabulary through reading.

Cluster IX, Gass, Meara and Brown, does not have any single obvious theme. Meara and Gass both wrote overview articles during this period, while Brown authored a paper on vocabulary learning strategies.

Cluster $\mathbf{X}$ is loosely attached to Cluster IV; Hulstijn, Greidanus and Hollander jointly authored a frequently cited paper dealing with incidental vocabulary acquisition. This paper also analyses the effectiveness of glosses.

Cluster XI, Johnson and Bransford, points to a series of papers co-authored by these two authors. Their work is mainly focussed on sentence comprehension.

Cluster XII, Selinker and Corder are best known for their work on Interlanguage.

Cluster XIII, Wittrock and Davis, like many of the sources in Cluster IV, deals with the use of glosses in L2 reading.

There are a number of striking features in this map. The most obvious feature is the very large increase in the density of the map compared with the maps of the earlier periods. This feature partly reflects a dramatic change in citation practices at this time, but it also reflects a general rise in research output during the period 1981-2000, and a specific increase in vocabulary research as evidenced in Figure 1. The second feature worth noting is the very large number of clusters in this map. In the earlier maps, we have just a handful of clusters, but here we have a much larger number, indicating that we have a wide variety of different approaches to L2 vocabulary acquisition during this period, each with its own distinct set of emphases. However, two of these clusters, Clusters I and II, are very densely interconnected with many common reference points and this seems to indicate the 
emergence of a very strong consensus about what questions L2 vocabulary research should address. Clusters I, II and III have no obvious antecedents in the earlier maps, and I interpret this to mean that the new consensus represents a sudden shift in the focus of vocabulary research. The theme that links these two clusters seems to be reading and comprehension - a slightly surprising feature, given the wider interest in communicative language learning during this period. In fact, the clusters located in the bottom half of the map, which include a distinctive group of L1 reading theorists in Cluster VI, do not appear to be involved in this consensus. They seem to be internally coherent in that the cluster members are frequently cited alongside each other, but these clusters have only loose co-citation links with the rest of the map and few links with each other.

The most striking feature of this map is the central role played by Paul Nation in linking the main cluster group together. Nation does not appear in the 1951-1980 map, though he was active during the latter part of this period. However, by 2000, he emerged as the biggest Significant Influence in L2 vocabulary research, with direct links to 8 of the 10 connected clusters in the map. Interestingly, the cluster analysis does not place Nation within either of the two largest clusters. Rather, he seems to belong to a cluster which contains people whose interests are less focused on L2 reading, and more concerned with strategies or with applications of corpus linguistics in language teaching. The fact that these people are frequently co-cited with Nation, but never cited with other vocabulary researchers is odd, but may simply reflect the fact that Nation's own work is much more wide ranging than some of the narrowly focussed work in Clusters I and II. Nation's work also tends to have a broader historical grounding than some of the other writers publishing in this period. His links with Cluster VII indicate that researchers outside the field are citing his work as prototypical of L2 vocabulary research.

In Figure 4, we note that some of the clusters are short-lived and the same feature can be found in Figure 5. The best example of this is the research strand exemplified by Clusters V and VI. This strand (another reading group) was very active in the earlier part of the 1981-2000 period, and its influence seems to have lessened after 1990. However, this group provides the only links between the main cluster grouping and the important cluster VII, the group focussed on Segalowitz. Cluster VII, which is strikingly well connected within itself, seems to consist of some heavyweight psychologists whose theoretical work is of great relevance to L2 vocabulary acquisition. The map suggests, however, that this work may have had only a limited influence on mainstream research as represented by Clusters I and II, and that this work is mediated through a small number of pivotal connections.

The legend to Figure 5 lists the most Significant Influences during this period. None of the Significant Influences in the previous period appears in this list, reinforcing the view that the new work represents something of a paradigm shift in L2 vocabulary research. For the first time here, we have a number of names which will be familiar to most researchers in the field. Nation, as we have already mentioned, has emerged as the outstanding Significant Influence during this period. This is most likely due to the seminal influence of his books (Nation, 1990, 2001), which summarised huge amounts of earlier research and rapidly became an 
essential source for vocabulary researchers. The list also includes a number of people who are not based in North America - Hulstijn, Bensoussan and Laufer illustrate this trend. Particularly striking, however, is the presence of Anderson and Herman, and Sternberg and Nagy in the list. These people are predominantly L1 reading researchers, and this indicates that $\mathrm{L} 1$ reading research was a particularly important influence during this period. Two other Significant Influences are worth commenting on in more detail. Krashen is best known for his work on the Monitor Model, a general theory of L2 performance which was very influential in the 1980s. Krashen published a particularly important paper in MLJ in 1989, arguing that most vocabulary is acquired by reading and not by direct instruction. This massively cited paper encapsulated an attractive idea for teachers, and influenced the direction research was to take out of all proportion to the strength of the data it reported. A much more interesting Significant Influence is Segalowitz who stands outside from the main cluster grouping. Segalowitz was an active member of the Montreal research group which featured in Figure 4, and should perhaps be seen as the successor to Lambert, the most Significant Influence in the 1950-1980 period. Segalowitz is particularly important because he provides the only link between research in L2 vocabulary acquisition and some important research in cognitive psychology which has implications for L2 vocabulary research. Segalowitz continues to work in the area of bilinguals' lexical performance, with a particular emphasis on lexical fluency. This is a complex topic with obvious implications for models of L2 lexical development, but on the evidence of Figure 5, its impact on mainstream research in L2 vocabulary seems to be slight.

To summarise, then, during the 1981-2000 period, MLJ published a lot of work on L2 vocabulary acquisition, but this work largely ignores all the previous work published in the journal. Instead, we find a marked focus on L2 reading skills, with a number of different approaches addressing this question. The main clusters rely heavily on Paul Nation's work, and a dense network of co-citations links Nation and the other members of the two main clusters. A few smaller clusters are loosely connected to the main cluster, but the members of these clusters are rarely cited alongside the members of the main clusters. The earlier work of this period is strongly influenced by the work of cognitive psychologists, but there is a suggestion that the more recent L2 research is becoming more autonomous and less outwardlooking.

\section{$3.4 \quad 2001-2010$}

Figure 6, which shows a map of the research published in the journal between 2001 and 2010, broadly confirms the trends we note in Figure 5. This map, which can be thought of as a map of current trends in L2 vocabulary research, needs to be treated with some caution, since it covers only 10 years of research and only 20 papers were published during this period. In spite of this, the number of cocitations in Figure 6 is about the same as the number of co-citations that Figure 5 is based on - the average number of sources cited in a paper published in this period is 71 . Setting a threshold of three co-citations for inclusion gives us a map consisting of 464 co-citations linking 68 authors in 7 clusters, one of which is detached. 


\section{perfetti_ca \\ stanovich_ke \\ cunningham_ae}

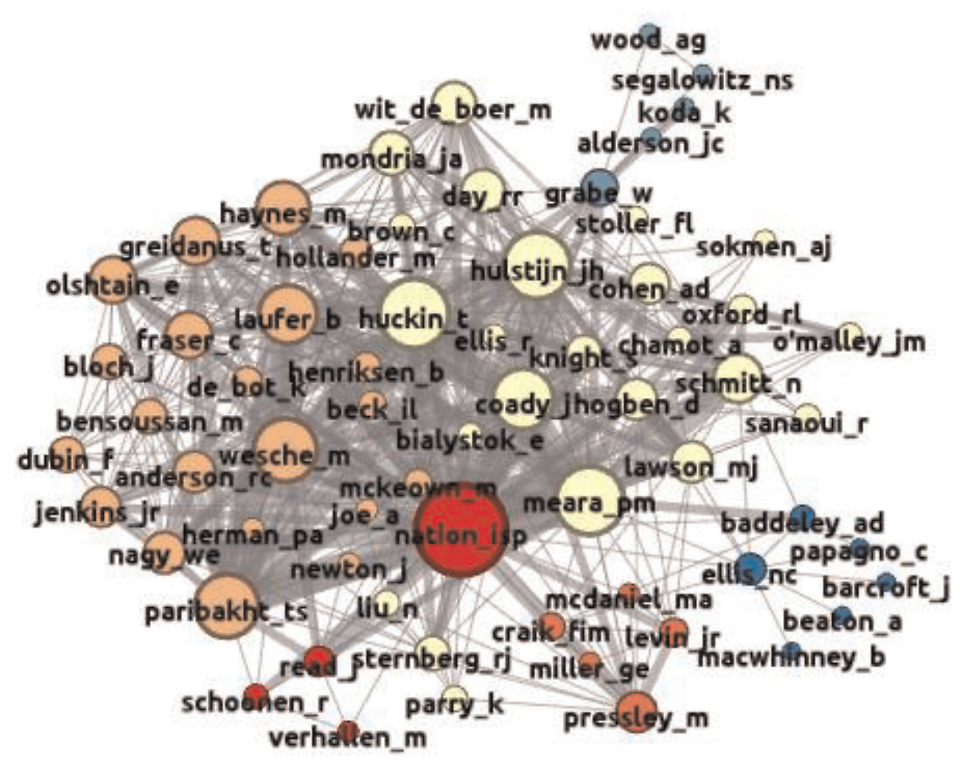

Figure 6. Co-citation analysis of vocabulary-focussed articles 2001-2010. Threshold for inclusion: three co-citations. The Significant Influences 2001-2010: Nation, Huckin, Meara, Hulstijn, Paribakht, Wesche, Coady, Laufer, Haynes, Schmitt, Greidanus, Fraser, Olshtain, Day and Mondria.

Gephi identifies seven clusters in this data.

Cluster I, with Nation, Wesche, Paribakht and Laufer as foci, is mainly concerned with L2 reading and particularly concerned with the uptake of unknown words through inferencing.

Cluster II, with Huckin, Hulstijn and Meara as foci, seems to consist mainly of a group of people who have written extensively about L2 vocabulary acquisition and use a wide variety of different approaches to this topic in their own research.

Cluster III, focussed on Nick Ellis, is a group of cognitive psychologists concerned with models of memory.

Cluster IV, the small cluster focussed on Grabe, mainly researches the mechanics of $\mathrm{L} 2$ reading.

Cluster V, focussed on Pressley, is a group whose work mainly deals with memory for words, with a particular emphasis on the keyword method.

Cluster VI, Read, Schoonen and Verhallen, is basically a testing group.

Cluster VII, the detached cluster comprising Stanovich, Perfetti and Cunningham, is another group of psychologists who work on L1 reading.

Again, this map has a number of features which need comment. The first feature is that all of the Significant Influences identified fit into the two main 
clusters. This suggests that the consolidation we noted in the 1981-2000 period seems to have intensified. The second feature is that the influence from Cognitive Psychology seems to have shifted. In this map, we have three separate groups of this sort. Connections with the rest of the network seem to be stronger than was the case in Figure 5, though Cluster VII is detached from the main clusters, and the other two clusters (Clusters III and IV) link mainly to specific individuals in Cluster II. Cluster II seems to be distinguished from Cluster I mainly by a surprising lack of co-citations with Cognitive Psychologists. The third feature is that, despite these changes, the clusters in Figure 6 can be readily identified with the clusters in Figure 5. This is the first time that we have seen any kind of continuity in these maps.

This continuity also appears in the list of Significant Influences in Figure 6. Four of the Significant Influences identified in Figure 5 - Nation, Hulstijn, Laufer and Haynes - continue to be Significant Influences in Figure 6, with Nation maintaining his position as by far the most co-cited source in the field. A number of people who played only a small role in Figure 5 have become Significant Influences in Figure 6 - notably Paribakht, Wesche, Meara and Schmitt. Fraser appears as a Significant Influence, despite not having a presence in the 1981-2000 map. Four Significant Influences in the 1981-2000 map do not appear in this map: Krashen, Carrell, Saragi and Meister.

\subsection{Overview}

We can now return briefly to the overview of MLJ research in Figure 2, which, in the light of the preceding analyses is much easier to interpret. Surprisingly, this map now appears to be largely organised along historical lines and it strongly emphasises the lack of continuity in the research published in MLJ.

The large central clusters, focussed on Nation and Hulstijn, consist mainly of people who are currently research-active. These clusters correspond to the central clusters in Figures 5 and 6. The large cluster at the eastern edge of the map, dominated by Segalowitz, captures the psychological theory that underpins a lot of the recent research. The small cluster that includes Carrell and Goodman captures the reading research that was characteristic of the 1970-1980 period, but is referred to only rarely in the most recent research. The cluster focussed on Thorndike and West at the south-east of the main clusters identifies the early research covering the period up to 1950 . This cluster is only tenuously attached to the main clusters. The large cluster at the south-east corner of the map contains the psycholinguists and sociolinguists from the earlier 1960 to 1970 period. This group now forms a detached island, indicating that though it was once important, it retains only limited relevance for current research.

\section{Discussion}

The question we posed in the introduction to this paper was whether an analysis of the vocabulary research in a single journal might provide a skeleton for a more detailed and in-depth study of how L2 vocabulary research has developed over the last 90 years. The answer to this question seems to be a tentative yes, but 
with some reservations. The analysis I have presented suggests that we can identify four broad periods of activity. 1916-1950 defines a period when most research was concerned with the development of reliable word lists for modern language teaching. 1951-1980 signals a short-lived shift away from word lists towards an approach that is more driven by cognitive psychology and sociolinguistics. 19812000 represents the start of modern research into L2 vocabulary acquisition, and the development of a broad consensus about what questions this research should be addressing. 2001-2010 sees the further consolidation of this consensus and the emergence of a new orthodoxy centred on Paul Nation's work. Most readers of this paper will find this is a plausible, if incomplete, account of how the field has developed since 1916. The central theme which seems to run through all the work reported here is a concern with reading in a second language - how to provide books that learners can usefully read, how reading skills can serve as an index of proficiency, how reading is an essential source of new vocabulary and how learners infer the meaning of new words they encounter in their reading. This emphasis, and its enduring role in the research, came as something of a surprise to me.

The question we have to ask now is whether the historical picture which emerges from MLJ is indeed an accurate portrayal of the way vocabulary research developed in the period under review. This question is surprisingly difficult to answer, as we do not have any similar studies based on other long-running journals against which this account could be compared. We might ask, for example, whether the apparent decline in vocabulary research between 1950 and 1980 really reflects what was going on in the research, or is it just the result of MLJ publishing fewer, longer articles? Was vocabulary research being published somewhere else because MLJ was hostile towards this sort of research? What was the editorial politics of MLJ during this period? Questions of this sort are obviously important, but need to be looked at in a wider context which is not currently available to us. Furthermore, even if we accept the raw figures from MLJ at face value there are a number of features which make it difficult to interpret the data. Most modern accounts of vocabulary research, for instance, do not make much reference to very early work in the field - Schmitt (2000), for example, cites in a very extensive bibliography only six papers published before 1945, two very early papers published in 1885 and 1889, and four later papers published in 1936, 1941, 1942 and 1946. Clearly, some further work is needed to establish how far this early work was influential outside the confines of MLJ. It is noticeable that some of the early papers published in MLJ refer to work which appeared in the Journal of Educational Psychology (JEP). The JEP papers are considerably more technical than the work appearing in MLJ and typically deal with questions of vocabulary assessment. This suggests that there might have been separate parallel developments in vocabulary research in other important journals appearing at this time. A preliminary trawl suggests that the JEP published a substantial number of papers dealing with aspects of vocabulary in a second language between 1916 and 2010, but the publication of these papers was heavily influenced by an explicit editorial policy. A co-citation analysis of this material might be able to put the MLJ papers in a wider context.

The North American focus provided by the Journal becomes less striking as we move away from the very early volumes, and by the time we get to the map 
shown in Figure 5, North Americans no longer have a monopoly of the places in the Significant Influences list. Nation is based in New Zealand, Hulstijn in the Netherlands, Bensoussan and Laufer in Israel. This internationalising trend becomes even more noticeable in the very recent research shown in Figure 6, where only a minority of the Significant Influences are based in the USA. Presumably, this trend reflects the growing importance of cheap air travel, the influence of better telecommunications and the growth of the internet on the way research develops. However, it is also possible that what we are picking up here is a move by US researchers away from vocabulary issues into some other area leaving a vacuum to be filled by researchers from elsewhere. Again, we cannot really assess this analysis without looking at comparable data in other journals.

Another feature of the maps based on the MLJ is the complete absence of any reference to some research initiatives that we might have expected to play a role in a more general history of research into vocabulary in an L2. There are three very obvious examples of this. Firstly, it is surprising that special purpose vocabularies do not appear as a cluster in any of the maps, as we might have expected this sort of work to be an area of some importance in the Journal. MLJ did in fact publish some work of this sort in the 1940s and early 1950s, but it appears to be practically rather than theoretically motivated, and the papers tend not to cite other work. In the 1940s, for example, the Journal published a number of "air vocabularies" word lists that might be of use to military aviators: fuel, take-off, landing strip, bomb, machine-gun, prisoner of war and so on - but these lists seem to be based on an ad hoc understanding of the situations involved, rather than something more principled that might have developed into a research theme. Secondly, and rather surprisingly given the early concerns of the journal, we find few signs of any research related to corpus linguistics, with the result that major initiatives like the COBUILD dictionary do not figure in the maps. In a comprehensive history, the Birmingham group and the Nottingham group, both based in the UK, might have been expected to play a larger role than they do here. Thirdly, there is a serious lack of engagement with some important strands of European research: again this is surprising given that the Journal is ostensibly concerned with the teaching of modern European languages, and that some early papers in the Journal report research visits to European centres where innovative work was taking place. A considerable amount of high-quality research was being undertaken, particularly in the Netherlands in the 1960s and 1970s. Both Spain and France also have a long tradition of researching vocabulary, with a particular emphasis on accessibility, and a significant omission from the maps is any mention of the Français fondamental project directed by Gougenheim (Gougenheim, Michéa, Rivenc, \& Sauvageot, 1956). Belgian and Dutch researchers were actively involved in developing word counts for the major European languages during the 1960s, and though this work was influential on the teaching of English, its impact on the foreign language teaching reported in MLJ seems to be negligible. This suggests that an analysis of a journal with professional aims similar to those of MLJ but with a different geographical base might generate a very different set of maps and provide a different looking history for the field.

Other topics which one might also expect to appear in a more comprehensive history are also missing from these maps. These topics include vocabulary testing 
and assessment, which we might have expected to be core areas for the MLJ, and the use of brain imaging methods to examine how L2 speakers perform, an area which we might have expected to be a feature of the more recent research. In general, the maps suggest that "outside influences" have become less important in the later issues of the journal. By the time we reach the more recent research, shown in Figure 6, all the Significant Influences are people who would primarily describe themselves as vocabulary researchers, and the input from other disciplines - L1 acquisition, psycholinguistics, language loss and cognitive psychology in particular - has fallen to alarmingly low levels. Where this work does appear in the maps, it tends to be channelled through a small number of people. Segalowitz, in Figure 5, is a particularly striking example of this role. Certainly, the picture which emerges in Figure 6 suggests that the vocabulary research published in MLJ has become increasingly monolithic, with very few points of reference outside itself. Whether this reflects a general characteristic of research or a more specific narrowing of horizons in the field at large remains to be seen.

It would be nice to be able to say that this analysis of Vocabulary research published in MLJ provides a reliable outline sketch of the vocabulary research work that was being undertaken throughout the twentieth century, and that all that remains to be done is to fill in some of the details. Certainly, the structure which emerges from the map in Figure 3 is a plausible account of how North American or more specifically USA - L2 vocabulary research developed during the twentieth century, and the broad lines of this map will be familiar to most researchers working in the field. However, I have also signalled some striking gaps in the maps, and most readers will be aware of other areas of vocabulary research that might have been added to that list. The best interpretation of these features seems to be that a single journal is perhaps not very representative of an entire field, but captures only a part of that work. This, of course, raises some interesting questions about the extent to which one journal's coverage differs from that of another, which journals best capture the available research and how many journals one would need to analyse in order to get a stable picture identifying most of the important features of research in a given time span. However, the earlier work reported in MLJ does not lend itself well to the co-citation analysis methods used in this paper, as the small number of citations means that we need to use very large timespans to get enough data, and this suggests that the co-citation approach may work well only with more recent sources. Nevertheless, even with the later research, the extended time spans are a problem. The specific time spans that I have used are motivated primarily by the need to group papers into similar sized data sets. To some extent, the divisions are arbitrary, and slightly different cluster analyses emerge when we divide the data up in other ways. Clearly, we need to ask whether extended time spans of the sort analysed here are best suited to capturing new developments in a field, or whether thinner slices from more journals might have provided us with better data. The maps do strongly suggest that there is a massive shift in research culture somewhere between 1980 and 1990. We cannot really pin these shifts down with any confidence but the MLJ data suggests that it would be worth looking at this period in much more detail. 


\section{Conclusions}

This paper has presented a co-citation analysis of the vocabulary research published in Modern Language Journal between 1916 and 2010, and has argued that the co-citation approach is able to throw some interesting light on the way the field has developed during this period. Using a single journal as a data source is not entirely satisfactory, as the picture which emerges from the co-citation maps is less complete than we might have hoped. However, it ought to be possible to supplement these maps with data from other journals and to establish how much data we need before a stable mapping emerges. Some problems with early citation practice were also noted. This suggests that the co-citation method might not produce reliable data from sources published before 1960, though data from later periods do seem to be very rich and capable of being mined in a number of different ways.

At first sight, the issues addressed here might appear to be rather academic. However, readers will be aware that bibliometric data of the sort reported in this paper are increasingly being used by research agencies to evaluate research outputs, and these evaluations have very significant impacts on the way we work. It would be reassuring to feel that these agencies are using data that we can have some confidence in. This is particularly important for research areas like L2 vocabulary acquisition, which historically have not had a single natural outlet.

\section{Notes}

1. Another comprehensive database is maintained by Paul Nation and can be found at http://www.victoria.ac.nz/lals/resources/vocrefs/bibliography. It is difficult to make direct comparisons between these two sources as they are differently structured. Nation's list is very comprehensive and organised by topic. However, it lacks the search facilities provided by the VARGA site. Readers interested in following up this comparison might find useful a paper by Murray, Ke, and Börner (2006), which explores the use of bibliometric analyses with personal bibliography files.

2. From Figure 3 onwards, the maps are all standardised using the same settings in the Gephi programme. Nodes are sized according to the number of connections they have with other nodes (their "degree"). It would have been possible to draw the maps so that the size of a node was directly determined by its degree. In this case, a node with $100^{\circ}$ would be 20 times larger than a node with $5^{\circ}$. This approach generated very large maps, which were impossible to reproduce legibly in the space available. As a compromise, the nodes in Figures 3-6 are scaled in relative terms. The nodes with the highest degree in each map are the same large size, and the nodes with the lowest degree are the same small size. Other nodes between these extremes are sized on a proportional scale. Since degree scores are not evenly spread out over the entire interval, we get rather a lot of smaller nodes, particularly in the larger maps. Full colour versions of these maps are available at http://www.lognostics/co/uk/maps.

\section{References}

Bastian, M., Heymann, S., \& Jacomy, M. (2009). Gephi: An open source software for exploring and manipulating networks. In International AAAI Conference on Weblogs and Social Media.

Gougenheim, G., Michéa, R., Rivenc, P., \& Sauvageot, A. (1956). L'élaboration du français fondamental (Ier degré) [The development of Français fondamental (Level 1)]. Paris: Didier. 
Hellqvist, B. (2010). Referencing in the Humanities and its implications for citation analysis. Journal of the American Society for Information Science and Technology, 61 (2), 310-318. doi:10.1002/asi.21256

Meara, P.M. (n.d.). The vocabulary acquisition research group archive (VARGA). Retrieved from http: //www.lognostics.co.uk/varga/

Meara, P.M. (2012). The bibliometrics of vocabulary acquisition: An exploratory study. RELC Journal, 43 (1), 7-22. doi:10.1177/0033688212439339

Meara, P.M. (forthcoming). Life before nation: Bibliometrics and L2 vocabulary studies in 1982.

Murray, C., Ke, W., \& Börner, K. (2006). Mapping scientific disciplines and author expertise based on personal bibliography files. In: Proceedings of the Conference on Information Visualization (pp. 258-263). Washington, DC: IEEE Computer Society.

Nation, I.S.P. (1990). Teaching and learning vocabulary. Boston, MA: Heinle and Heinle.

Nation, I.S.P. (2001). Learning vocabulary in another language. Cambridge: Cambridge University Press. doi:10.1017/CBO9781139524759

Price, D. (1965). Networks of scientific papers. Science 149 (3683), 510-515. doi:10. 1126/science.149.3683.510

Price, D. (1986). Little science, big science... and beyond. New York: Columbia University Press.

Schmitt, N. (2000). Vocabulary in language teaching. Cambridge: Cambridge University Press.

Small, H. (1973). Co-citation in the scientific literature: A new measure of the relationship between two documents. Journal of the American Society for Information Science, 24, 265-269. doi:10.1002/asi.4630240406

Smith, R.C. (Ed.). (2003). Teaching English as a foreign language, 1912-1936: Pioneers of ELT (Vol. 3). London: Routledge.

White, H.D., \& Griffith, B.C. (1981). Author cocitation: A literature measure of intellectual structure. Journal of the American Society for Information Science, 32, 163-171. doi:10.1002/asi.4630320302

Zuccala, A. (2006). Modeling the invisible college. Journal of the American Society for Information Science and Technology, 57 (2), 152-168. doi:10.1002/asi. 20256 


\section{Appendix: The 201 papers used as source material for this report (listed by date).}

Bagster-Collins, E.W. (1918). A brief study showing the relation between the vocabulary and treatment of the annotated reading text. $M L J, 2$ (8), 341-345.

Weigel, J.C. (1919). The acquisition of a vocabulary. $M L J, 3$ (8), 339-360.

Bovée, A.G. (1919). Teaching vocabulary by the direct method. MLJ, 4 (1), 63-72.

Wadepuhl, W. (1923). A standardized vocabulary for elementary German. MLJ, 8 (1), 23-30.

Keller, M.V. (1923). The necessity of teaching a basic vocabulary in modern language work. $M L J, 8$ (1), 35-40.

Jamieson, E.I. (1924). A standardized vocabulary for elementary Spanish. $M L J, 8$ (6), 325-333.

Hubman, S. (1924). The business of getting a vocabulary. MLJ, 9 (3), 159-166.

Wilkins, E.H. (1924). Suggestions as to method in making a vocabulary. MLJ, 9 (3), 167-169.

Morgan, B.Q. (1925). The Chicago MLT adopts a German vocabulary. MLJ, 9 (7), 397-457.

Cartwright, C.W. (1925). A study of the vocabularies of eleven Spanish grammars and fifteen Spanish reading texts. $M L J, 10$ (1), 1-14.

Eddy, H.M. (1926). The French element in English. MLJ, 10 (5), 271-280.

Morgan, C. (1926). Vocabulary analysis of a second year Spanish text. MLJ, 10 (7), 427-430.

Wood, B.D. (1927). A comparative study of the vocabularies of sixteen French textbooks. MLJ, 11 (5), 265-289.

Johnson, C.L. (1927). Vocabulary difficulty and textbook selection. MLJ, 11 (5), 290-297.

Broom, E., \& Contreras, M.S. (1926). A background vocabulary list in Spanish. MLJ, 11 (7), 459-463.

Dexter, E.F. (1928). An analysis of a first year Spanish vocabulary. MLJ, 12 (2), 272-278.

Gay, L.M. (1928). Reflections on the Henmon Word Book. MLJ, 12 (5), 365-369.

Roulston, R.B. (1929). A plea for more and better special vocabularies. MLJ, 13 (4), 304307.

Simmons, L.V. T. (1929). A vocabulary count based on three German dramas. MLJ, 14 (1), 33-36.

Blackburn, M. (1930). An analysis of the vocabulary of two recent French grammars. $M L J$, 14 (6), 431-441.

West, M. (1930). Speaking vocabulary in a foreign language. MLJ, 14 (7), 509-521.

Maronpot, R.P. (1930). Teaching and testing vocabulary on a one-language basis. MLJ, 14 (7), 554-560.

Talmey, M. (1930). Word composition in a logical language. $M L J, 15$ (3), 200-214.

Engel, E.F. (1931). The use of a standardized vocabulary in beginning German. MLJ, 15 (4), 281-291.

Breageale, E. (1931). The value and use of the new word lists. MLJ, 15 (4), 298-299.

Fotos, J.T. (1931). Word and idiom frequency counts in French and their value. MLJ, 15 (5), 344-353.

FitzGerald, T. (1931). Textbook vocabularies. MLJ, 16 (2), 135-139.

Coleman, A.P. (1931). The basic vocabulary in Polish. MLJ, 16 (2), 140-146.

Scatori, S. (1932). Deceptive cognates in Spanish. MLJ, 16 (5), 396-401.

Hagboldt, P.J. (1932). Types of memory in language study. MLJ, 16 (7), 583-590. 
Arnold, H.H. (1932). A list of graded vocabularies and a method of grading. MLJ, 16 (8), $644-655$.

Handschin, C.H. (1932). The question of the most economical learning of the German vocabulary. MLJ, 17 (3), 195-199.

Rose, E. (1933). Vocabularies in German textbooks. MLJ, 17 (5), 334-341.

Bement, N.S., \& Smith, E.M. (1933). Standardizing French vocabulary for beginners. $M L J$, 17 (8), 579-591.

Grimes, M.E. (1933). French noun endings and vocabulary building. MLJ, 18 (2), 93-99.

Morgan, B.Q. (1933). A minimum standard vocabulary for German. MLJ, 18 (3), 145-152.

Haygood, J.D. (1933). The amount and composition of a minimum essential French reading vocabulary. $M L J, 18$ (3), 177-189.

Bovée, A.G., Coleman, A., Eddy, H.M., Russell, P., \& Tharp, J.B. (1934). A basic French vocabulary. MLJ, 18 (4), 238-274.

Porterfield, A.W. (1934). The treatment of vocabularies in textbooks. MLJ, 18 (7), 451-459.

Morgan, B.Q. (1934). Derivatives in the new basic French vocabulary. MLJ, 18 (7), 460-462.

Schobinger, E. (1934). Adventures with words. MLJ, 19 (1), 9-14.

Tharp, J.B. (1934). The basic French vocabulary and its use. MLJ, 19 (2), 123-131.

Gilbert, L.C., \& Loobourow, G.C. (1935). High-school spelling of English and foreign language words. $M L J, 19$ (4), 266-270.

Wilson, W.E. (1935). A supplementary vocabulary list for Spanish composition. MLJ, 19 (6), 439-440.

Jones, W.K. (1935). Deceptive doubles: Twin words--With a difference. MLJ, 20 (1), 15-18.

Skinner, L.H. (1935). A comparative study of the vocabularies of forty-five Italian textbooks. MLJ, 20 (2), 67-84.

Kaulfers, W.V. (1936). Interpretative vocabulary-exercises for beginners in French. MLJ, 20 (7), 396-402.

Skinner, L.H. (1936). An analysis of the vocabulary-difficulty of forty-five Italian textbooks. MLJ, 20 (7), 411-415.

Vowles, G.R. (1936). Norwegian loan-words. MLJ, 21 (1), 16.

Kurath, W., \& Stalnaker, J.M. (1936). Two German vocabulary tests. MLJ, 21 (2), 95-102.

Sharp, S.L. (1936). German textbook vocabularies and a supplementary dictionary. $M L J, 21$ (3), 157-161.

West, M. (1937). The present position in vocabulary selection for foreign language teaching. MLJ, 21 (6), 433-437.

Coleman, A. (1937). A minimum French idiom list. MLJ, 21 (8), 569-576.

Kennedy, G.A. (1937). A minimum vocabulary in modern Chinese. MLJ, 21 (8), 587-592.

Walpole, H. (1937). The theory of definition and its application to vocabulary limitation. MLJ, 21 (6), 398-402.

Lorenz, C.M. (1937). Foreign language words and phrases in American periodicals. MLJ, 22 (2), 92-103.

West, M. (1937). "The reading approach" and "the new method system". MLJ, 22 (3), 220 222 .

Hagboldt, P. (1938). The work of Michael West. MLJ, 22 (6), 411-419.

Wade, G.E. (1938). A note on Spanish vocabulary. $M L J, 22$ (6), 433-436.

Smith, H.E. (1938). Increase your vocabulary. MLJ, 23 (1), 41-45.

Vocabulary Learning and Instruction, 3 (1), 1-28. 
Tate, H.L. (1938). Two experiments in reading-vocabulary building. MLJ, 23 (3), 214-218. Gibson, A.D. (1939). The vocabulary of sports in French. MLJ, 23 (5), 350-356.

Tharp, J.B. (1939). The measurement of vocabulary difficulty. MLJ, 24 (3), 169-178.

Miller, M.M., Farr, G. (1939). Student recognition of some Spanish-English cognates. MLJ, 24 (3), 216-220.

Delcourt, J. (1940). On the impressive possibilities of the English vocabulary. $M L J, 25$ (1), 4-13.

Morgan, B.Q. (1940). Cognates and the minimum standard German vocabulary. MLJ, 25 (1), 26-30.

Lembi, D.P., \& Kaulfers, W.V. (1940). French expressions used in English: An exploratory vocabulary unit for the first week of beginning French or General Language. $M L J, 25$ (3), 174-186.

Johnston, M.C. (1941). Spanish-English cognates of high frequency. MLJ, 25 (5), 405-417.

Stevens, L.C. (1941). The problem of vocabulary levels in teaching French. MLJ, 25 (8), 633-636.

Henninger, G.A. (1942). Some questions for a language-vocabulary course. MLJ, 26 (1), $27-34$.

Morgan, E.A. (1942). Teaching the gender of nouns. MLJ, 26 (5), 352-357.

Moore, A.Z. (1942). An experiment designed to measure the comparative achievement in vocabulary and reading ability of second year classes in French and Spanish. MLJ, 26 (5), $358-360$.

Scanlon, C. (1942). The purpose of graded texts. MLJ, 26 (6), 421-423.

Redick, J. (1942). Another aid in teaching vocabulary. MLJ, 26 (8), 587-588.

Peacock, V.L. (1942). Foreign words in everyday reading matter. MLJ, 26 (8), 589-591.

Dummer, E.H. (1943). A new vocabulary test. MLJ, 27 (1), 21-24.

Stevens, L.C. (1943). Textbook vocabularies and deceptive cognates in Spanish. MLJ, 27 (2), $116-118$.

Huebner, T. (1943). An air vocabulary of 100 Words. MLJ, 27 (5) 353-355.

Lindgren, H.C. (1943). Understanding foreign terms used in English. MLJ, 27 (7), 505-507.

Eaton, H.S. (1943). A new course in Basic Language. MLJ, 27 (8), 578-581.

Henninger, G.A. (1944). In defense of dictionaries and definitions. MLJ, 28 (1), 29-39.

Liebesny, H.J. (1944). Vocabulary learning enjoyable: Making a proper use of proper dictionaries. $M L J, 28$ (2), 182-189.

Richards, I.A. (1945). BASIC English. MLJ, 29 (1), 60-65.

Willis, E. (1944). Environmental vocabulary. MLJ, 28 (3), 239-245.

Seibert, L.C. (1945). A study of the practice of guessing word meanings from a context. MLJ, 29 (4), 296-322.

Cook, P. (1945). Iowa place names of foreign origin. $M L J, 29$ (7), 617-628.

Steinbugler, J.L. (1945). English-German vocabulary. MLJ, 29 (8), 698-704.

Vance, D.G. (1946). Correlation of Latin and Spanish. MLJ, 30 (4), 208-216.

Greiner, O.A. (1946). Words, not grammar. MLJ, 30 (6), 347-351.

Vittorini, D. (1946). Formation of Italian nouns from English equivalents. MLJ, 30 (8), 604611.

Fitz Gerald, T.A. (1947). A plea for graded reading texts. $M L J, 31$ (6), 359-362. 
Vittorini, D. (1947). Formation of Italian adjectives and verbs from English equivalents. MLJ, 31 (3), 138-146.

Russo, G.A. (1947). A combined Italian word list. $M L J, 31$ (4), 218-240.

Josselson, H.H. (1947). Russian word count. MLJ, 31 (7), 422-425.

Vittorini, D. (1947). Cultural material and vocabulary in the study of romance languages. MLJ, 31 (8), 486-488.

Eoff, S., \& Bull, W.E. (1948). A semantic approach to the teaching of foreign languages. $M L J, 32$ (1), 3-13.

Iacobelli, M. (1949). The semantic discipline. $M L J, 33$ (1), 16-22.

Wuest, A. (1949). French vocabulary aids. MLJ, 33 (2), 122-123.

Bull, W.E. (1950). Spanish word counts: Theory and practice. MLJ, 34 (1), 18-26.

Abraham, R.D. (1950). Fixed order of coordinates: A study in comparative lexicography. MLJ, 34 (4), 276-287.

Resnick, S. (1950). English words in Spanish literature. MLJ, 34 (3), 204-208.

Russell, H.J. (1950). What is readable and what is not readable in a foreign language? MLJ, 34 (4), 270-275.

Parker, F. (1952). The teaching and development of Russian vocabulary. $M L J, 36$ (3), 135 136.

Shaewitz, L. (1953). Semantics for modern languages. $M L J, 37$ (4), 177-180.

Spaulding, S. (1953). Three-dimensional word repetition in reading material. MLJ, 37 (5), $226-230$.

Lockwood, E., \& Lockwood, W.B. (1953). Vocabulary difficulties in English and German. MLJ, 37 (6), 287-292.

Nabholz, N. (1953). Applied philology. MLJ, 37 (7), 347-350.

Prince, J.R. (1954). Philology at work. MLJ, 38 (2), 75-79.

Kownacki, S. (1955). Teaching foreign languages in specialized fields. MLJ, 39 (7), 351-352.

Richards, E.S., \& Appel, J.E. (1956). The effects of written words in beginning Spanish. $M L J, 40$ (3), 29-133.

Crawford, P., \& Vittorini, D. (1956). English cognates and Spanish masculine nouns. $M L J$, 40 (7), 391-395.

Spaulding, S. (1956). A Spanish readability formula. $M L J, 40$ (8), 433-441.

Keppler, K. (1957). Problems of German-English dictionary making. MLJ, 41 (1), 26-29.

Hammer, C. (1957). Stress the German-English Cognates! MLJ, 41 (4), 177-182.

Ianucci, J.E. (1957). Meaning discrimination in bilingual dictionaries: A new lexicographical technique. $M L J, 41$ (6), 272-281.

Hietsch, O. (1958). Meaning discrimination in modern lexicography. MLJ, 42 (5), 232-234.

Salling, A. (1958). An essay in comparative vocabulary study. MLJ, 42 (5), 222-225.

Chandler, R.E. (1958). Spanish-Portuguese transfer. $M L J, 42$ (7), 329-336.

Beberfall, L. (1959). The verb and the beginning student of Spanish. MLJ, 43 (1), 26-28.

Volman, R.J. (1959). Similarities of gender in basic Spanish and French vocabularies. MLJ, 43 (1), 21.

Spotts, L.H. (1959). Foundations of vocabulary selection for the teaching of Hebrew in America. MLJ, 43 (6), 281-287.

Di Blasi, S. (1959). Problems in Italian lexicography. $M L J, 43$ (7), 316-320.

Lowe, R. (1960). French name words in the classroom. MLJ, 44 (2), 71-74.

Vocabulary Learning and Instruction, 3 (1), 1-28. 
Meyersteen, R.S. (1960). Bilingual dictionaries and applied linguistics. MLJ, 44 (3), 163-167. Russo, J.A. (1962). An Italian idiom list. MLJ, 46 (1), 14-21.

Lambert, W.E. (1963). Psychological approaches to the study of language: Part I: On learning, thinking and human abilities. $M L J, 47$ (2), 51-62.

Lambert, W.E. (1963). Psychological approaches to the study of language: Part II: On second-language learning and bilingualism. MLJ, 47 (3), 114-121.

Hakes, D.T. (1965). Psychological aspects of bilingualism. MLJ, 49 (4), 220-227.

Hadlich, R.L. (1965). Lexical contrastive analysis. $M L J, 49$ (7), 426-429.

Pimsleur, P. (1967). A memory schedule. $M L J, 51$ (2), 73-75.

Preller, A.G. (1967). Some problems involved in compiling word frequency lists. $M L J, 51$ (7), 399-402.

Adkins, P.G. (1968). Teaching idioms and figures of speech to non-native speakers of English. MLJ, 52 (3), 148-152.

Cooper, R.L., \& Greenfield, L. (1969). Word frequency estimation as a measure of degree of bilingualism. MLJ, 53 (3), 163-166.

Cooper, R.L. (1969). Two contextualized measures of degree of bilingualism. MLJ, 53 (3), 172-178.

Berney, T.D., \& Cooper, R.L. (1969). Semantic independence and degree of bilingualism in two communities. MLJ, 53 (3), 182-185.

Fertig, S., \& Fishman, J.A. (1969). Some measures of the interaction between language, domain and semantic dimension in bilinguals. MLJ, 53 (4), 244-249.

Ronch, J., Cooper, R.L., \& Fishman, J.A. (1969). Word naming and usage scores for a sample of Yiddish-English bilinguals. MLJ, 53 (4), 232-235.

Darian, S. (1969). Backgrounds of modern language teaching: Sweet, Jespersen, and Palmer. MLJ, 53 (8), 545-550.

Smith, P. (1969). Teaching vocabulary. MLJ, 53 (8), 531-553.

Leong, C.K. (1972). A study of written Chinese vocabulary. MLJ, 56 (4), 230-234.

Baetens Beardsmore, H., \& Lee, E.J. (1973). Teaching English as a foreign language for special purposes. $M L J, 57(7), 343-348$.

Reinert, H. (1976). One picture is worth a thousand words? Not necessarily! MLJ, 60 (4), 160-168.

Cummins, J. (1977). Cognitive factors associated with the attainment of intermediate levels of bilingual skills. MLJ, 61 (1/2), 3-12.

Cornu, A.-M. (1979). The first step in vocabulary teaching. MLJ, 63 (5/6), 262-272.

Cartwright, D.S., \& Nickerson, C.A. (1979). An empirical thesaurus: Meaning norms for ninety common words. $M L J, 63$ (8), 442-447.

Sugano, M.Z. (1981). The idiom in Spanish language teaching. MLJ, 65 (1), 59-66.

Banta, F.G. (1981). Teaching German vocabulary: The use of English cognates and common loan words. MLJ, 65 (2), 129-136.

Vari-Cartier, P. (1981). Development and validation of a new instrument to assess the readability of Spanish prose. $M L J, 65$ (2), 141-148.

Odlin, T., \& Natalicio, D. (1982). Some characteristics of word classification in a second language. $M L J, 66$ (1), 34-38.

Adams, S.J. (1982). Scripts and the recognition of unfamiliar vocabulary: Enhancing second language reading skills. $M L J, 66$ (2), 155-159. 
Schulz, R.A. (1983). From word to meaning: Foreign language reading instruction after the elementary course. $M L J, 67$ (2), 127-134.

Bahrick, H.P. (1984). Fifty years of second language attrition: Implications for programmatic research. $M L J, 68$ (2), 105-118.

Martin, M. (1984). Advanced vocabulary teaching: The problem of synonyms. $M L J, 68$ (2), $130-137$.

Ostyn, P., \& Godin, P. (1985). RALEX: An alternative approach to language teaching. $M L J$, 69 (4), 346-355.

Crow, J.T. (1986). Receptive vocabulary acquisition for reading comprehension. $M L J, 70$ (3), $242-250$.

Murphy, D.T. (1986). Approaches to the verb and Russian word counts. MLJ, 70 (3), 258262.

Barnett, M.A. (1986). Syntactic and lexical/semantic skill in foreign language reading: Importance and interaction. $M L J, 70$ (4), 343-349.

Keller, H. (1987). Pedagogical wishes for a machine dictionary: An example from Russian. MLJ, 71 (1), 12-17.

Hayes, E.B. (1988). Encoding strategies used by native and non-native readers of Chinese Mandarin. MLJ, 72 (2), 188-195.

Bolton, S. (1988). A comparative study of basic German vocabulary lists. MLJ, 72 (2), 196200.

Davis, J.N. (1989). Facilitating effects of marginal glosses on foreign language reading. MLJ, 73 (1), 41-48.

Koda, K. (1989). Development of L2 intraword orthographic sensitivity and decoding skills. MLJ, 73 (1), 51-64.

Kern, R.G. (1989). Second language reading strategy instruction: Its effects on comprehension and word inference ability. MLJ, 73 (2), 135-149.

Krashen, S.D. (1989). We acquire vocabulary and spelling by reading: Additional evidence for the input hypothesis. MLJ, 73 (4), 440-464.

Bland, S.K., Noblitt, J.S., Armington, S., \& Gay, G. (1990). The naive lexical hypothesis: Evidence from computer-assisted language learning. $M L J, 74$ (4), 44-450.

Laufer, B. (1991). The development of L2 lexis in the expression of the advanced learner. MLJ, 75 (4), 440-448.

Hulstijn, J.H. (1993). When do foreign-language readers look up the meaning of unfamiliar words? The influence of task and learner variables. MLJ, 77 (2), 139-147.

Knight, S. (1994). Dictionary use while reading: The effects on comprehension and vocabulary acquisition for students of different verbal abilities. MLJ, 78 (3), 285-299.

Sanaoui, R. (1995). Adult learners' approaches to learning vocabulary in second languages. MLJ, 79 (1), 15-28.

Chun, D.L., \& Plass, J.L. (1996). Effects of multimedia annotations on vocabulary acquisition. $M L J, 80$ (2), 183-198.

Hulstijn, J.H., Hollander, M., \& Greidanus, T. (1996). Incidental vocabulary learning by advanced foreign language students: The influence of marginal glosses, dictionary use, and reoccurrence of unknown words. $M L J, 80$ (3), 327-339.

Ke, C.R. (1996). An empirical study on the relationship between Chinese character recognition and production. $M L J, 80$ (3), 340-349.

Koda, K. (1996). L2 word recognition research: A critical review. MLJ, 80 (4), 450-460.

Prince, P. (1996). Second language vocabulary learning: The role of context versus translations as a function of proficiency. $M L J, 80$ (4), 478-493. 
Laufer, B., \& Hadar, L. (1997). Assessing the effectiveness of monolingual, bilingual, and "bilingualised" dictionaries in the comprehension and production of new words. $M L J, 81$ (2), 189-196.

Mori, Y. (1998). Effects of first language and phonological accessibility on kanji recognition. $M L J, 82$ (1), 69-82.

Grace, C. (1998). Retention of word meanings inferred from context and sentence-level translations: Implications for the design of beginning-level CALL software. MLJ, 82 (4), $533-544$.

Kojic-Sabo, I., \& Lightbown, P.M. (1999). Students' approaches to vocabulary learning and their relationship to success. $M L J, 83$ (2), 176-192.

Mori, Y. (1999). Beliefs about language learning and their relationship to the ability to integrate information from word parts and context in interpreting novel kanji words. $M L J$, 83 (4), 534-554.

Wesche, M., \& Paribakht, T.S. (2000). Reading-based exercises in second language vocabulary learning: An introspective study. MLJ, 84 (2), 196-213.

Grace, C.A. (2000). Gender differences: Vocabulary retention and access to translations for beginning language learners in CALL. MLJ, 84 (2), 214-224.

Khaldieh, S.A. (2001). The relationship between knowledge of I'raab, lexical knowledge, and reading comprehension of nonnative readers of Arabic. MLJ, 85 (3), 416-431.

Greidanus, T., \& Nienhuis, L. (2001). Testing the quality of word knowledge in a second language by means of word associations: Types of distractors and types of associations. MLJ, 85 (4), 567-577.

Jones, L.C., \& Plass, J.L. (2002). Supporting listening comprehension and vocabulary acquisition in French with multimedia annotations. MLJ, 86 (4), 546-561.

Barcroft, J. (2003). Effects of questions about word meaning during L2 Spanish lexical learning. $M L J, 87$ (4), 546-561.

Frantzen, D. (2003). Factors affecting how second language Spanish students derive meaning from context. $M L J, 87$ (2), 168-199.

Fan, M.Y. (2003). Frequency of use, perceived usefulness, and actual usefulness of second language vocabulary strategies: A study of Hong Kong learners. MLJ, 87 (2), 222-241.

Morin, R. (2003). Derivational morphological analysis as a strategy for vocabulary acquisition in Spanish. MLJ, 87 (2), 200-221.

Mori, Y. (2003). The roles of context and word morphology in learning new kanji words. MLJ, 87 (3), 404-420.

Jiang, N. (2004). Semantic transfer and its implications for vocabulary teaching in a second language. $M L J, 88$ (3), 416-432.

Fukkink, R.G., Hulstijn, J.H., \& Simis, A. (2005). Does training in second-language word recognition skills affect reading comprehension? An experimental study. $M L J, 89(1), 54-75$.

Greidanus, T., Beks, B., \& Wakely, R. (2005). Testing the development of French word knowledge by advanced Dutch- and English-speaking learners and native speakers. MLJ, 89 (2), 221-233.

Chikamatsu, N. (2006). Developmental word recognition: A study of L1 English readers of L2 Japanese. $M L J, 90$ (1), 67-85.

Sagarra, N., \& Alba, M. (2006). The key is in the keyword: L2 vocabulary learning methods with beginning learners of Spanish. MLJ, 90 (2), 228-243.

Nassaji, H. (2006). The relationship between depth of vocabulary knowledge and L2 learners' lexical inferencing strategy use and success. $M L J, 90$ (3), 387-401.

Trofimovich, P., \& Gatbonton, E. (2006). Repetition and focus on form in processing L2 Spanish words: Implications for pronunciation instruction. MLJ, 90 (4), 519-535. 
Shen, H.H., \& Ke, C.R. (2007). Radical awareness and word acquisition among nonnative learners of Chinese. MLJ, 91 (1), 97-111.

Pavlenko, A., \& Driagina, V. (2007). Russian emotion vocabulary in American learners' narratives. $M L J, 91$ (2), 213-234.

Chieh-Fang, H. (2008). Rate of acquiring and processing L2 color words in relation to L1 phonological awareness. MLJ, 92 (1), 39-52.

Kim, Y.J. (2008). The contribution of collaborative and individual tasks to the acquisition of L2 vocabulary. $M L J, 92$ (1), 114-130.

Hansen, G.F. (2010). Word recognition in Arabic. MLJ, 94 (4), 567-581. 